\title{
A Study Of Photoelectrical Characteristics Of (CdS/CdTe) Heterojunction
}

\author{
Bashar A.H. AL-abbasy \\ University of Mosul,college of Engineering \\ Electrical Eng. Dept.
}

\begin{abstract}
:
In this work, we report the photoelectrical properties of the (CdS/CdTe) structure as a function of the reverse bias voltage, light intensity and incident power wavelength. The investigated photodetection performance is located in the visible light spectrum situated at wavelength range $(488-595 \mathrm{~nm})$ and the maximum photocurrent at $(505 \mathrm{~nm})$. The photodetection parameters such as quantum efficiency, responsivity, and detectivity have been studied as a function of incident power wavelength at different reverse bias voltages. These studies gave somewhat low values of such parameters which describe the performance of any photodetector.
\end{abstract}

Keywords: photoelectrical characteristics, CdS/CdTe heterojunction

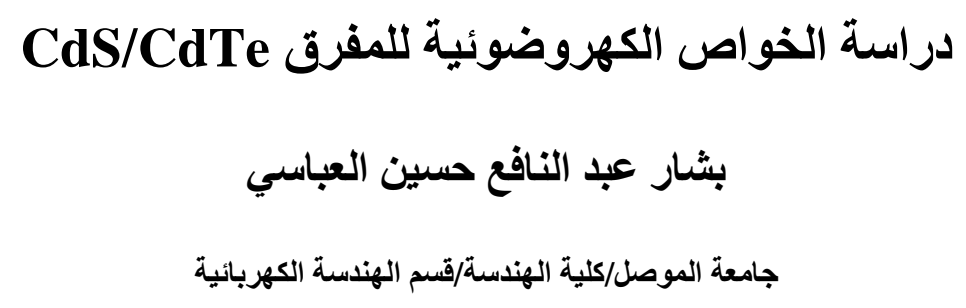

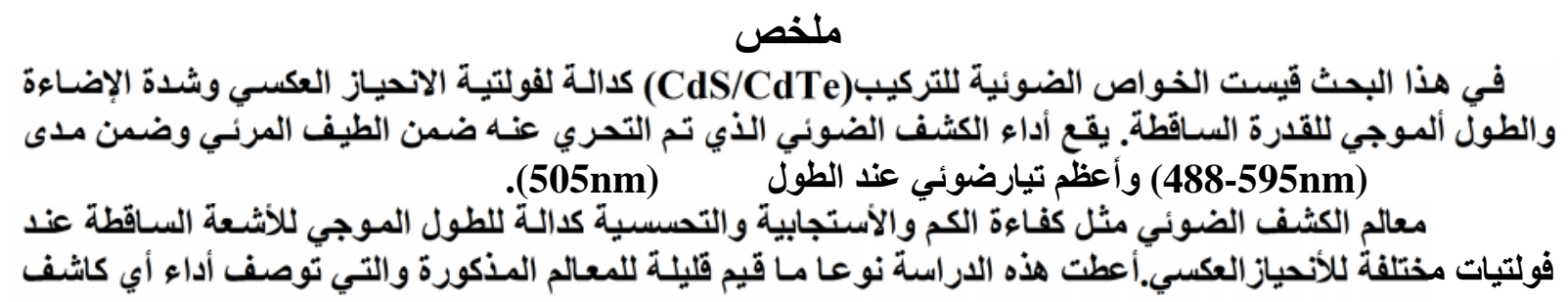

Received : $16-2-2010$

Excepted : 12 - 5 - 2010 


\section{Introduction:}

The semiconductor has many interesting properties which make it very useful in microelectronics applications. Such properties as photo-sensitive effect exhibits a variant resistive and photo-electricity behaviour [1].

Cadimum telluride, a II-VI compound presents various properties (energy gap about $1.5 \mathrm{ev,}$ large atomic numbers of the components $\left(\mathrm{Z}_{\mathrm{cd}}=48, \mathrm{Z}_{\mathrm{Te}}=52\right)$, direct fundamental transition, $\mathrm{n}$ or p-type conductivity, etc), making it attractive for applications as different as gamma and $\mathrm{x}$ ray detectors and photovoltaic devices [2].

Cadimum sulfide (CdS) is one of the well-known II-VI compound semiconductors used for optoelectronic materials, such as solar cells and photodetectors [3].

The optoelectronic properties of $(\mathrm{CdS} / \mathrm{CdTe})$ heterojunction structure depend on the characteristics of the large band-gap material (window layer), small band-gap (absorber material), the junction interface and on the deposition conditions. One of the distinguishing properties of heterojunctions which was brought out is the "Window Effect" associated with the photo-characteristics of such junction. If the illumination is incident on the wide-gap semiconductor and the wavelength is within the range $\mathrm{Eg}_{1}>\mathrm{hv}>\mathrm{Eg}_{2}$ then photogeneration of electron-hole pairs occurs only in the narrow-gap semiconductor, i.e, the wide-gap semiconductor is transparent to the incident radiation. The advantage of this is two folds: firstly, as the junction in the narrow-gap semiconductor can be located far from the surface, surface recombination of minority carriers is thereby reduced. Secondly, because no absorption occurs in the wide-gap material, it can be made sufficiently thick and of high enough conductivity to reduce spreading resistance losses to an acceptable low level. The first advantage can, however, be lost if the interface region between the semiconductors has a high trap or defect density which act as recombination centers [4]. The CdTe was recognized early on as a good solar cell absorber layer and $n-C d S(E g=2.42 \mathrm{ev})$ forms one side of the electrical junction and acts as a window layer [5]. Jesco and Michael [6] found undoped CdTe films are very responsive to light at room temperature and the illumination is $100 \mathrm{mw}$ $\mathrm{cm}^{-2}$ of light from tungsten iodine lamp. The CdS/CdTe structure as a solar cell of $13 \%$ conversion efficiency are studied by M.T.S. NAIR et al [7]. The maximum efficiency of $\mathrm{CdS} / \mathrm{CdTe}$ solar cells can probably improved by optimizing some steps of the manufacturing process such as the contact to CdTe and the thickness of the CdS layer [8].The thickness of the CdS layer limits short wavelength cell response [9].Most researchers like Halliday [10] and Viswanathan [11] studied carefully the thin film CdTe/CdS structure to process the influence of impurties and the formation of an effective back contact to CdTe solar cells that impact on device performance.

This work is concerned with the $\left(\mathrm{I}_{\mathrm{ph}}-\mathrm{V}\right)$ characteristics at different illumination levels by using Halogene source light. The effect of reversed bias voltage on $\left(\mathrm{I}_{\mathrm{ph}}-\varnothing\right)$ characteristics is studied. The quantum efficiency, spectral responsivity and detectivity were measured over the wavelength range $(404-695 \mathrm{~nm})$ by using selective filters. All of the experiments were carried out on a CdS/CdTe structure deposited by Balzer vacuum evaporated unit.

\section{Device fabrication:}

The devices used in the present investigation were fabricated as follows:

The thermal vacuum evaporated $\mathrm{Al}$ film of $2000{ }^{\circ} \mathrm{A}$ thickness deposited on the micro-glass substrate for back contact. 
The thermal vacuum CdTe film of $5000{ }^{\circ} \mathrm{A}$ thickness was deposited on part of $\mathrm{Al}$ back contact using suitable mask. And a thin film of CdS with $5000{ }^{\circ} \mathrm{A}$ thickness was deposited on the CdTe film.

In the final step an Al-gate grid contacts like fingers of $2000{ }^{\circ} \mathrm{A}$ thickness were deposited.

\section{(CdS/CdTe) Photo-characteristics: Effect of reverse bias on the photocurrent of $(\mathrm{CdS} / \mathrm{CdTe})$ heterojunction:}

The ratio of photocurrent to dark current is more important than the magnitude of the photocurrent density $\left(\mathrm{J}_{\mathrm{ph}}\right)[12,13]$. When the $(\mathrm{CdS} / \mathrm{CdTe})$ structure was used as a photodiode, it operates in the third quadrant of the (I-V) characteristics, i.e. with a reverse biased configuration, and hence the photo-generation occurred within the depletion layer $(w)$. The appropriate width (w) was chosen as a compromise between the sensitivity (larger w) and the speed of response (small w) and this was done by reverse bias variation.

Figure (1) represents the $\left(\mathrm{I}_{\mathrm{ph}}\right.$ versus $\mathrm{V}_{\mathrm{R}}$ ) characteristics under various lightintensities $\left(\emptyset_{\mathrm{s}}\right)$ for $(\mathrm{CdS} / \mathrm{CdTe}) \mathrm{HJ}$ with a grid contact, and the net area of generation is equal to $\left(6 \mathrm{~cm}^{2}\right)$. This grid contact yields a high collection efficiency.

This figure indicates a proportional of the $\left(\mathrm{I}_{\mathrm{ph}}\right)$ with the reverse- biasing voltage for a certain-light level which reveals an increasing of the separation efficiency as the electric field is increased, i.e, minimizing the recombination probability, and the

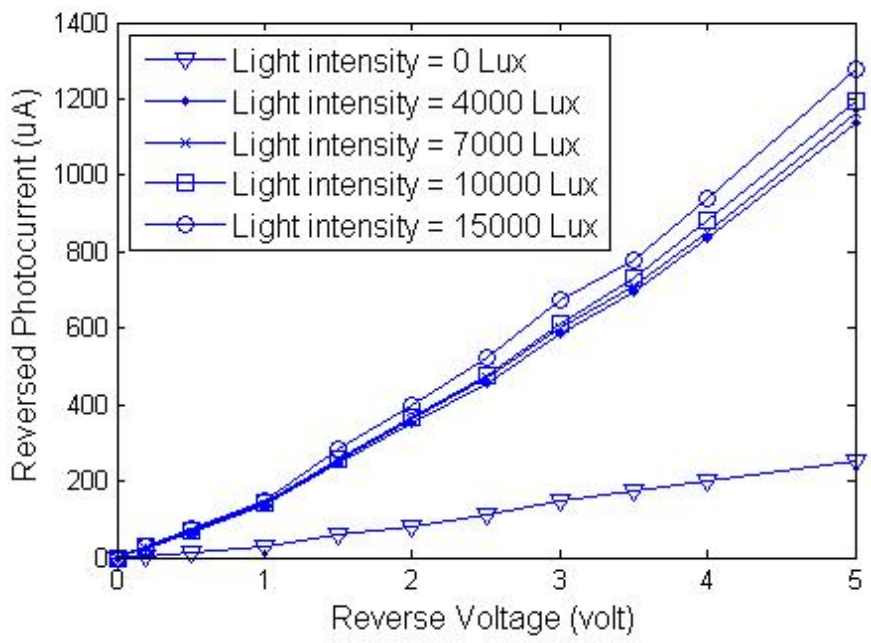

Fig. 1. $\left(\mathrm{I}_{\mathrm{Ph}}-\mathrm{V}_{\mathrm{R}}\right)$ photo-voltage characteristic for $\mathrm{CdS} / \mathrm{CdTe}$ at various light intensity $(\varnothing)$ carrier transit time $\left(t_{r}\right)$ is decreased $\left(t_{r}=\right.$ $\mathrm{w} / \mathrm{v}_{\mathrm{d}}$ and $\mathrm{v}_{\mathrm{d}}=\mathrm{E}$ is the drift velocity and $\mathrm{E}$ is the external field). Therefore, the gain of the generated photocurrent is increased according to the following equation [14]:

$$
\text { Gain }=\frac{\tau}{t_{r}}
$$

Where $\tau$ is the carrier lifetime.

The generated photocurrent has a tendency toward the linear variation versus applied reverse voltage which indicates that the photo-generated carriers are not completely collected. This can be explained by the high photo-generation which exceeds the device collection at certain reverse biasing.

There is also a jump in the current when the light change from dark condition $\left(\varnothing_{\mathrm{s}}=\right.$ zero $)$ to $\left(\emptyset_{\mathrm{s}}=15000 \mathrm{Lux}\right)$ which is due to the increased CdS conductivity, i.e. high photo-generated of electron-hole pairs which permits the current to flow easily. 


\section{Light-Intensity effect on the photo-generated current:}

Figure (2) represents the $\left(\mathrm{I}_{\mathrm{ph}}\right.$ versus $\left.\emptyset_{\mathrm{s}}\right)$ characteristics under various reverse biasing voltage. This figure indicates that the photocurrent $\left(\mathrm{I}_{\mathrm{ph}}\right)$ has small values when the device is under a low biasing voltage. This means that the electric field strength is not enough, then the depletion region width (w) is not wide which results in a small generation volume.

While for a high biasing voltage, the photocurrent is higher and it varies almost linearly with the light-intensity $[12,15]$. This is due to increase the depletion layer width (w)

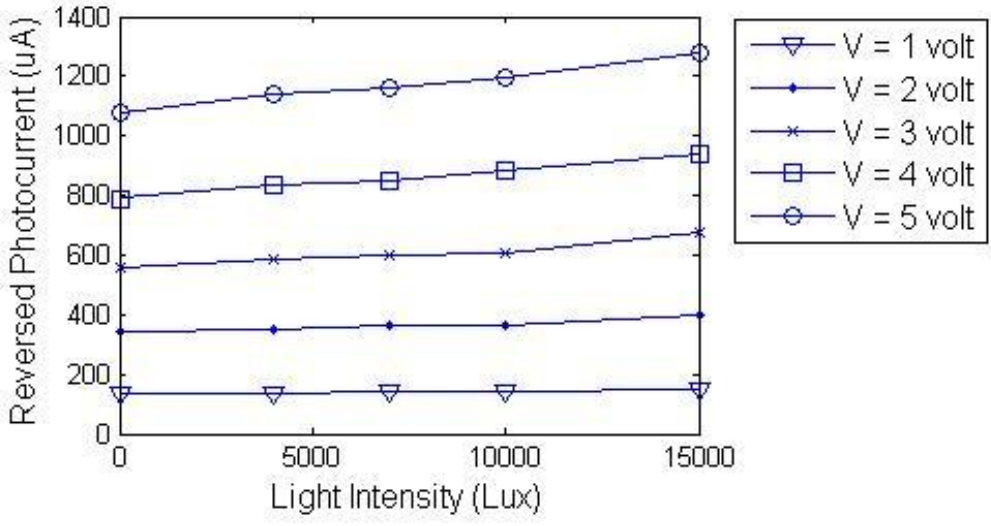

Fig.2. The $\left(\mathrm{I}_{\mathrm{Ph}}-\varnothing\right)$ photo-characteristic for $\mathrm{CdS} / \mathrm{CdTe}$ at various $\mathrm{V}_{\mathrm{R}}$ and consequently an increasing of electron-hole pair generation as the photon-flux $\left(\varnothing_{\mathrm{s}}\right)$ increase. This result is in a good agreement with the expression of the photocurrent density $\left(\mathrm{J}_{\mathrm{ph}}\right)$ given by the following equation [13]:

$$
J_{p h}=q Q_{0} Q_{c 0}\left[1-\left(\frac{e^{-\alpha w}}{1+\alpha L_{n}}\right)\right]
$$

Where $\mathrm{q}$ is the electron charge, $\left(\mathrm{Q}_{\mathrm{o}}\right)$ is the total incident photon flux (photon/sec.cm $\left.{ }^{2}\right),\left(\mathrm{Q}_{\mathrm{co}}\right)$ is the overall collection efficiency, $(\alpha)$ is the absorption coefficient, (w) is the depletion layer width, and $\left(\mathrm{L}_{\mathrm{n}}\right)$ is the diffusion length for electrons.

The CdTe thickness (absorber layer) which is fabricated is somewhat not enough to achieve high absorpance because the CdTe thickness is proportional to optical absorption coefficient $(\alpha)$ which controls the number of the absorbed photons that contributes to the light current [16]. For this reason, most researches used a thickness of CdTe in the range $(1 \mu \mathrm{m}-10 \mu \mathrm{m})[5,8,16]$.

\section{Effect of Incident Radiation wavelength $(\lambda)$ on the photogenerated current:}

Figure (3) and (4) represent the effect of the incident radiation wavelength $(\lambda)$ at $\left(V_{R}=6\right.$ volt) and (3 volt) for (CdS/CdTe) structure respectively.

In general, the response of the above structure can be divided into three different regions. The first region situated in the wavelength range $(404-488 \mathrm{~nm})$ which is characterized by the decrease in photocurrent with the decrease in wavelength due to the absorption of the incident photons at the surface far from the effect of electric field in the depletion region. The second region gives a maximum photocurrent around $(510 \mathrm{~nm})$ due to the increase of transmittance coefficient of CdS layer at $\lambda=500 \mathrm{~nm}$ which caused a more generation of electron-hole pairs in the depletion layer[16]. The third region situated in the wavelength range $(510-670 \mathrm{~nm})$ is 
characterized by the decreasing in photocurrent which refers to the decreasing in the optical absorbance and an increase in the incident radiation wavelength $(\lambda)[17,18]$, but there is a break in the curve at the range (541-580nm) associated with trap defects in CdS films [4].

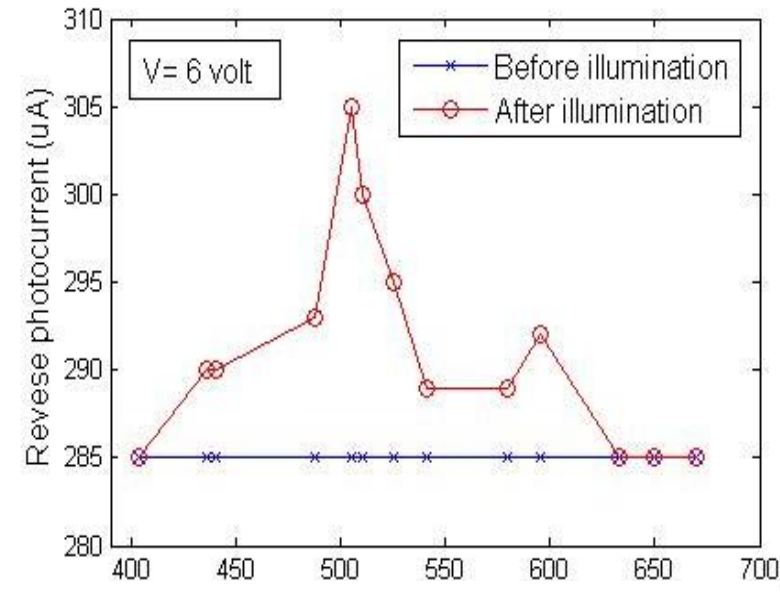

Fig.3. Reversed photocurrent spectrum for $\mathrm{CdS} / \mathrm{CdTe}$ at $\mathrm{V}_{\mathrm{R}}=6 \mathrm{v}$

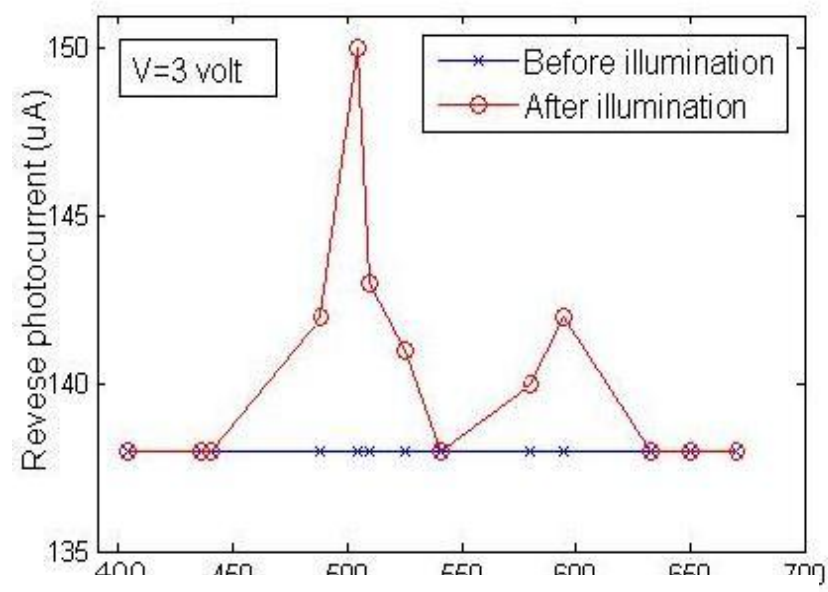

Fig.4. Reversed photocurrent spectrum for $\mathrm{CdS} / \mathrm{CdTe}$ at $\mathrm{V}_{\mathrm{R}}=3 \mathrm{v}$

The high CdS thickness $5000{ }^{\circ} \mathrm{A}$ (window or buffer layer) which fabricated is perform a high uniformity film to avoid short circuit effect, but reducing the transmittance in the visible range of the spectrum [8]. Also, the CdS layer acts as a window layer at about $\lambda=500 \mathrm{~nm}$ because the optical absorption coefficient $(\alpha)$ of the CdS is high at $\lambda<500 \mathrm{~nm}$ [16]. For this reason, most researches used a CdS thickness in the range (100nm- 300nm) $[5,8,16]$.

\section{Effect of Incident radiation wavelength $(\lambda)$ on the quantum efficiency:}

Figure (5) represents the quantum efficiency dependence on the incident radiation wavelength at different reverse bias. The quantum efficiency depends upon the photocurrent and the photon energy according to the following equation [14]:

$\eta=\left[\frac{I_{p h}}{q}\right]\left[\frac{P_{o p t}}{h v}\right]^{-1} * 100$

where $\mathrm{I}_{\mathrm{ph}}$ is the photogenerated current from the absorption of incident optical power $\left(\mathrm{P}_{\mathrm{opt}}\right)$ at a wavelength $(\lambda)$ [corresponding to a photon energy (hv)] at any reverse bias. The above relationship can be written again after the substitution (hv) by hv $=1.24 / \lambda$

$\eta=\left[\frac{I_{p h}}{q * P_{o p t}}\right]\left[\frac{1.24}{\lambda}\right] * 100$

The quantum efficiency is the number of electron-hole pairs generated for each incident photon, therefore, the explanation of the effect of the $(\lambda)$ on photocurrent can be used here to interpret the effect of $(\lambda)$ on quantum efficiency. Also, the effect of reverse bias on quantum 
efficiency was very clear that the number of electron-hole pairs increased as the depletion region increased and these generated carriers contribute to the output current.

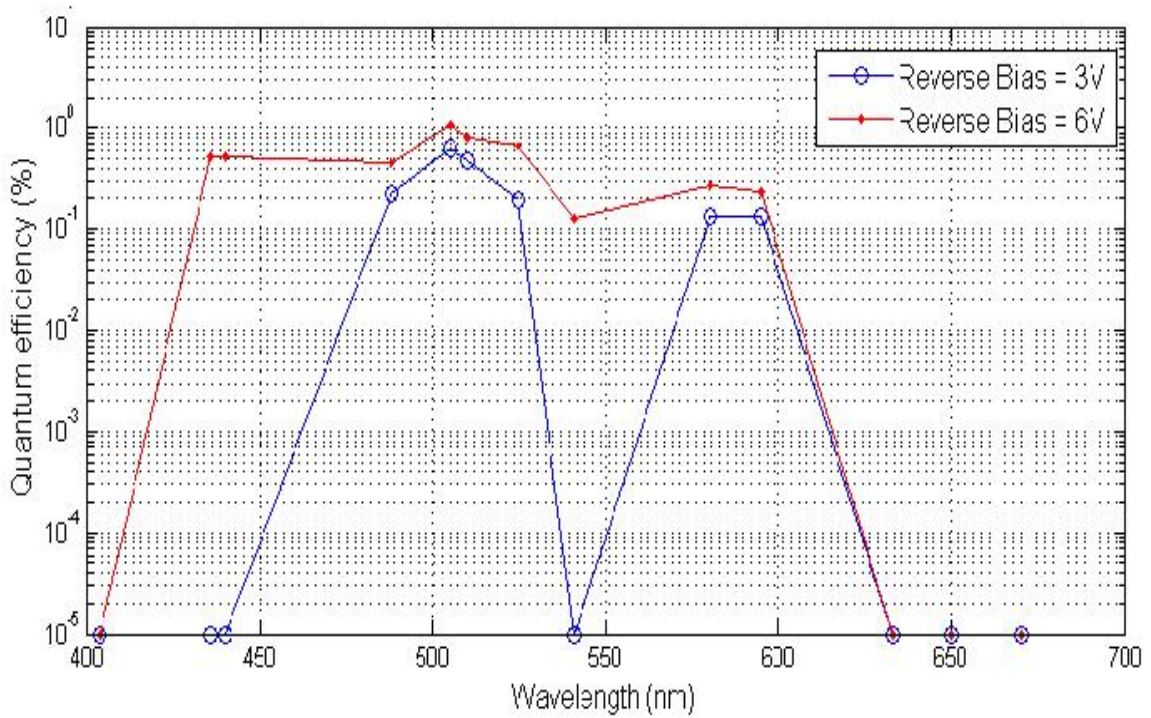

Fig. 5. Quantum efficiency spectrum for CdS/CdTe at various $V_{R}$

It is obvious from fig.(5) that the maximum efficiency obtained was (1.06\%) which can be considered that the $(\mathrm{CdS} / \mathrm{CdTe}) \mathrm{HJ}$ as it fabricated has a low quantum efficiency to use it as a photodetector in the visible region. This low quantum efficiency may be attributed to the higher density of defects at the boundary interface, appearing due to the bands discontinuities, then this should increase the recombination rate at the boundary interface and hampers the carriers transition from one semiconductor to the other [19]. The advantage of the junction in the narrow-gap semiconductor can be located far from the surface, surface recombination of minority carriers is thereby reduced. This advantage can however be lost if the interface region between the semiconductors has a high trap or defect density which acts as recombination centers [4].

At the junction with CdS, mixed CdTe-CdS phases can be formed: a sulfar rich CdTe phase, $\mathrm{CdTe}_{1-\mathrm{x}} \mathrm{S}_{\mathrm{x}}$ with $\mathrm{x}<<1$, in the CdTe absorber, and a tellurium rich CdS phase, CdS ${ }_{1-\mathrm{y}}$ $\mathrm{Te}_{\mathrm{y}}$ with $\mathrm{y}<<1$, in the CdS window. The bandgap $\operatorname{Eg}(\mathrm{x})$ of the mixed phases depends parabolically on the composition $\mathrm{x}$ or $\mathrm{y}$. This effect shifts the quantum efficiency of $\mathrm{CdTe} / \mathrm{CdS}$ cells around $\lambda=520 \mathrm{~nm}$ due to the $\mathrm{CdS}_{1-\mathrm{y}} \mathrm{Te}_{\mathrm{y}}$ mixed phase enhances the window absorption (this is a loss) and around $\lambda=860 \mathrm{~nm}$ due to the $\mathrm{CdTe}_{1-\mathrm{x}} \mathrm{S}_{\mathrm{x}}$ mixed phase enhances the absorption (this is a gain)[16].

To improve the quantum efficiency, a transparent conducting oxide layer (TCO) must be fabricated after CdS deposition layer. The function of the TCO is to provide a highly transparent and conductive contact to the $\mathrm{CdS}$ window layer [5]. In this case, a low scattering of the incident light is available which leads to increase the incoming photon absorbed in the CdTe layer.

\section{Effect of Incident Radiation wavelength $(\lambda)$ on the Responsivity and Detectivity:}

Figure (6) represents the responsivity dependence on the $(\lambda)$. The responsivity is the ratio of the photocurrent to the incident power. The measured responsivity in $(\mathrm{CdS} / \mathrm{CdTe}) \mathrm{HJ}$ depends on the photocurrent, therefore, the effect of $(\lambda)$ on the responsivity corresponds to the effect of $(\lambda)$ on the photocurrent which has been studied previously. 


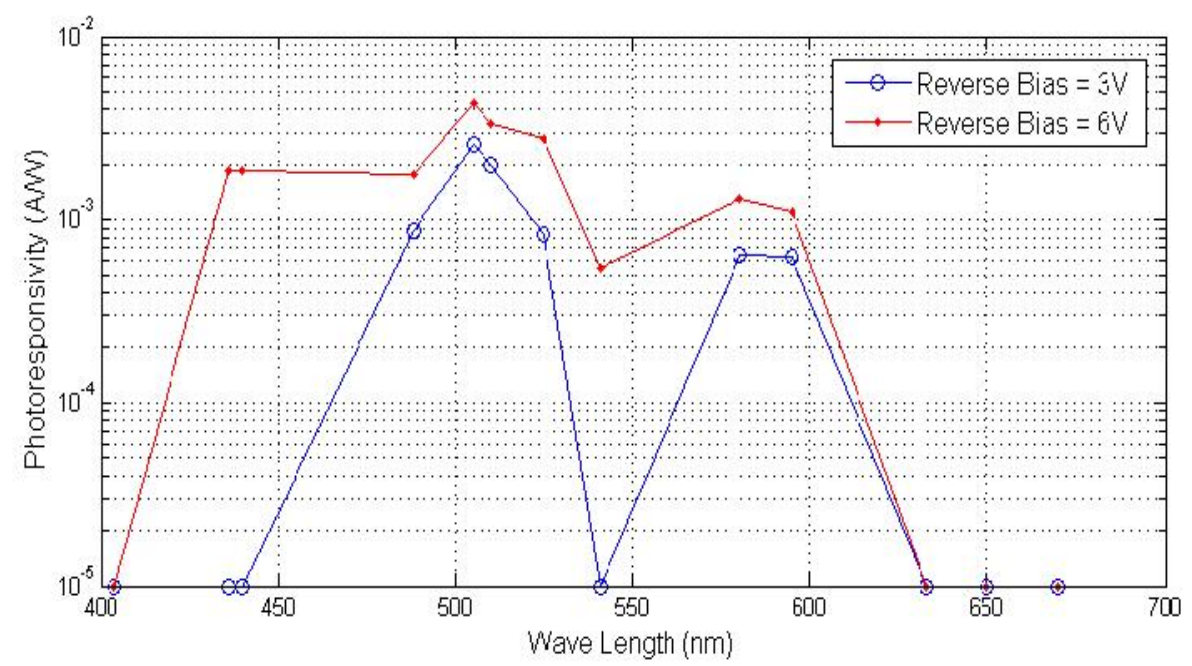

Fig. 6. Photo-responsivity spectrum for CdS/CdTe under various $V_{R}$

The high thickness of $\mathrm{CdS} 5000{ }^{\circ} \mathrm{A}$ (window layer) causes a reduced response in the (400$500 \mathrm{~nm}$ ) wavelength region [16].

The effect of the interdiffusion of CdTe into CdS is to curtail the spectral response at its low $\lambda$ end by reducing the window transmission. On the other hand, incorporation of some $\mathrm{CdS}$ into CdTe ,the CdTe extends the spectral response to longer wavelength [5].

Figure (7) represents the detectivity dependence on the $(\lambda)$ at different reverse bias voltage. It is defined as the signal-to-noise ratio produced per watt of radient flux incident on the detector.

$D=\frac{1}{N E P}$

Where NEP (Noise Equivalent Power) is the incident power which produces an output signal (r.m.s.) equal to the electrical noise signal (r.m.s) for a noise bandwidth $1 \mathrm{HZ}$.

NEP can be defined as:

$$
N E P=\frac{I_{n}(A / H z)}{S(A / w)}
$$

Where $I_{n}$ is the noise current (small current which flows when reverse voltage is applied to a photodetector under dark conditions), and $S$ is the responsivity which is defined by the equation:

$S=\frac{I_{p h}}{P_{o p t}}$

Substituting equations (6\&7) in (5), we can obtain the following equation:

$$
D=\left(\frac{I_{p h}}{I_{n}}\right) *\left(\frac{1}{P_{i}}\right)
$$




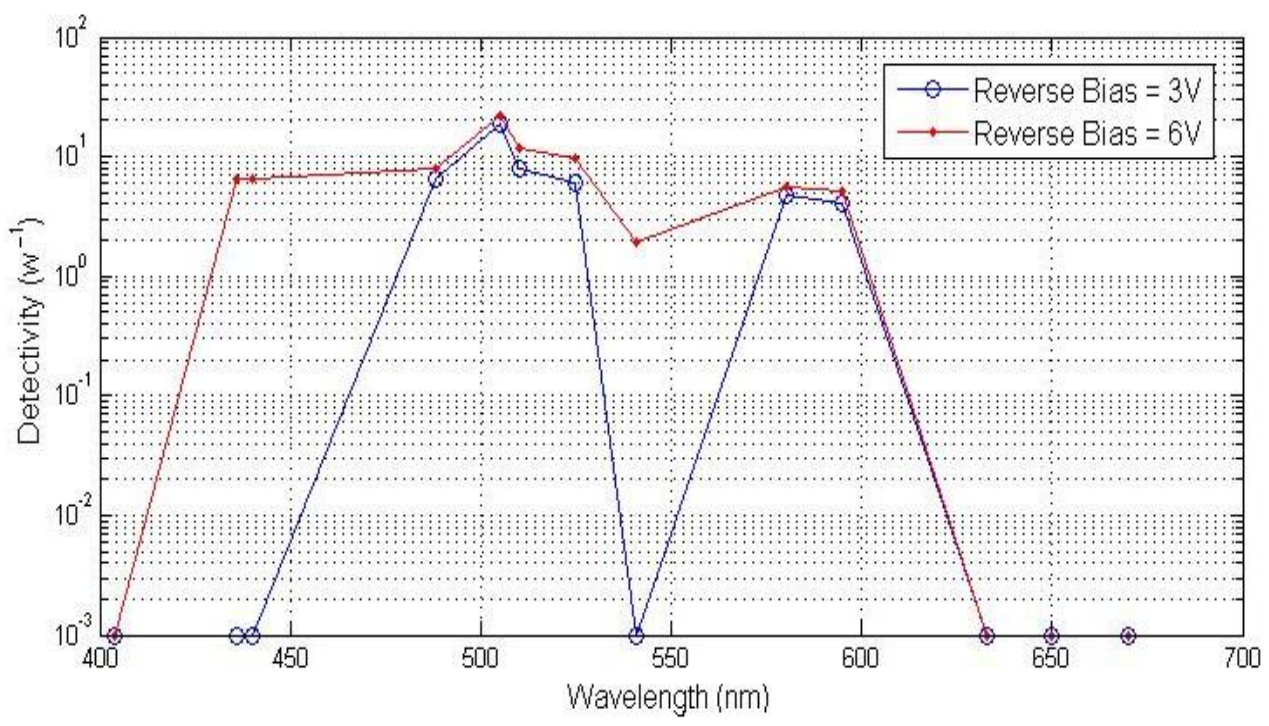

Fig. 7. Detectivity spectrum for CdS/CdTe under various $V_{R}$

The NEP and detectivity is respectively the first and second of two figures of merit which describe the photodetector performance.

From the definition of the detectivity in equation (8), the dark current was approximately constant through the measurement, therefore the detectivity depends upon the variation of the photocurrent under different wavelengths.

\section{Conclusions:-}

On the basis of experimental results realized in this research, it is possible to conclude the following view-points:

i) A proportional increasing of the photocurrent $\left(\mathrm{I}_{\mathrm{ph}}\right)$ of the $(\mathrm{CdS} / \mathrm{CdTe})$ HJ with reverse bias voltage $\left(V_{R}\right)$ at a certain light-intensity which reveals an increasing of the separation of the electron-hole pairs in depletion layer as the electric field is increased.

ii) Any increasing in the photon-flux $\left(\emptyset_{\mathrm{S}}\right)$ which causes an increasing of electron-hole pairs generation due to the increasing of depletion layer width (W) for high biasing voltage.

iii) The spectral response of the photocurrent for the $(\mathrm{CdS} / \mathrm{CdTe}) \mathrm{HJ}$ at certain reverse biasing can be divided into three regions which are situated at wavelength (400-670nm). Rrsults show that this approach can use the $(\mathrm{CdS} / \mathrm{CdTe}) \mathrm{HJ}$ in the visible light spectrum $(440-600 \mathrm{~nm})$ and the maximum photocurrent at $(505 \mathrm{~nm})$.

IV) Similar spectral response for photodetection parameters (Quantum efficiency, Responsivity and Detectivity) have been obtained in this work. Low values somewhat were observed for the parameters which describe the performance of any photodetector.

V) The choice of the optimum thickness for CdS thin film (window layer) and CdTe thin film (absorber layer) was very important and must be relevant because it affected directly on the absorption of the incident photons and limited the spectral parameters of the structure (Quantum efficiency, Responsivity, and Detectivity). 


\section{References:}

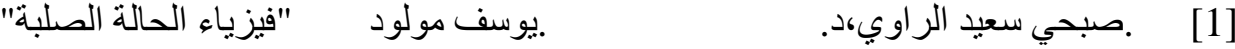

$$
\begin{aligned}
& 1988
\end{aligned}
$$

[2] Philippe Lemasson "Electrochemical study of phosphorus-doped cadmium telluride "J.phys.D: Appl.phys.22(1989) 952-955.

[3] AKIO KUROYANAGI AND TOSHIKAZU SUDA "Properties of CdS:In thin films grown by ionized deposition". Thin solid films,1989,vol.162,247-254.

[4] F.M. Livigstone,R.M.De La Rue, and W.Duncan "P.Si-n.CdS heterojunction photodetectors"phys.stat.sol.(a),595,1987.

[5] K. Durose , P.R. Edwards, D.P. Halliday "Material aspects of CdTe/CdS solar cells" Journal of Crystal Growth, (1999), 733-742.

[6] Jesko A von windheim and Michael cocivera "Variation of resistivity of copper-doped cadmium telluride prepared by electrodeposition " J.phys.D:Appl.phys.23(1990) 581-586.

[7] M.T.S. NAIR, P.K. NAIR AND J.CAMDOS "Effect of bath temperature on the optoelectronic characteristics of chemically deposited CdS thin films "Thin solid films, vol.161,1988,21-34.

[8] L.R.Cruz; V.D.Falcao; C.L.Ferreira; W.A.Pinheiro; I.G.Mattoso; R.M.P.Alves "MANUFACTURING PROCEDURES OF A CdS/CdTe THIN FILM SOLAR CELL" Revista Brasileira de Aplicacoes de Vacuo, v.25, n.1, 15-19, 2006.

[9] Walter A. Wohlmuth "Thin Film CdTe Module Manufacturing" CS MANTECH Conference, May 18th-21st, 2009, Tampa, Florida, USA.

[10] D.P.Halliday, M Emziane, K.Durose, A.Bosio, N.Romeo "EFFECTS OF IMPURITIES IN CdTe/CdS STRUCTURES: TOWARDS ENHANCED DEVICE EFFICIENCIES" 2006 IEEE.

[11] V. Viswanathan, D.L.Morel and C.S.Ferekids "RF SPUTTER ETCH AS A SURFACE CLEANING PROCESS FOR CdTe SOLAR CELLS" 2005 IEEE.

[12] A.F.Nadoss "Characterization and vacuum deposition of CdS layer on silicon wafers "M.sc. thesis, univ. of Mosul, college of science, 1989.

[13]:J.P. Ponpon "A review of ohmic and rectifying contacts on cadmium telluride " solid state Electronics, vol.28, No.7 pp.689-706,1985.

[14] S.M. Sze "Semiconductor devices physics and technology " John and Sons, 1985.

[15] N.V.Joshi and Alicia serfaty "Detectivity of the photo-sensors: A Reevaluation " International Journal of Infrared and Millimeter waves, vol.10.,No.9,1989.

[16] J. Poortsmans and V. Arkhipov "Thin Film Solar Cells" 2006 John Wiley \& Sons, Ltd.

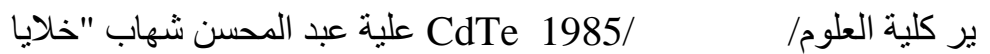

[18] Yasunobu Nashimoto, Shgeru Fuyuki, Tadamasa Akutagawa and Sohachiro Hayakawa "photoelectronic properties of P-type CdTe in a Aqueous solution " Japanese Journal of Applied physics, vol.20,No.3,1981,pp.565-570.

[19] Kovalenko P.A., Korotkov V.A., Panasjuk L.M. "Transversal and longitudinal photoeffect in heterojunction between elementary semiconductors and II-VI compounds " proc. Int. conf. on phys. \& chem.. of semiconductors heterojunctions vol.2, pp.363371,1971 .

The work was carried out at the college of Engg. University of Mosul 